\title{
UMBRELLA MONOPOLE ANTENNA FOR 5G APPLICATIONS
}

\author{
${ }^{1}$ Paulen Aulia Lutfia, ${ }^{2}$ Nurhayati Nurhayati, ${ }^{3}$ Samuel Prasad Jones Christydass \\ ${ }^{1,2}$ Negeri Surabaya University in Indonesia \\ ${ }^{3}$ Electronics and Communication Engineering, K. Ramakrishnan College of Technology, India \\ paulenaulialutfia@gmail.com \\ nurhayati@unesa.ac.id \\ prasadjoness.ece@krct.ac.in
}

\begin{abstract}
Umbrella Monopole Antenna (UMA) proposed in this paper for 5G application. We designed four models of UMA, i.e: UMA-A, UMA-B, UMA-C, and UMA-D. The antenna has a curvature in the patch as an umbrella shape with a feeding shape a microstrip feed line. Four variations of the patch antenna have been designed and get different performance in VSWR, surface current, and directivity. The proposed antenna has a wide bandwidth that operates $8 \mathrm{GHz}-30 \mathrm{GHz}$ with VSWR $<2 \mathrm{~dB}$. The Increasing of directivity is reached for UMA-A, UMA-C, UMA-D, and UMAB, i.e: $6.38 \mathrm{dBi}, 7.97 \mathrm{dBi}, 8,84 \mathrm{dBi}$, and 9,15 dBi respectively at $24 \mathrm{GHz}$. The maximum gain has been reached for UMA-B of 9.15. The lowest frequency that has a return loss of $10 \mathrm{~dB}$ has resulted for UMA-D in the frequency around 5 GHz. All of the UMA antennas can be applied for $5 \mathrm{G}$ mmwave applications at $24 \mathrm{GHz}$ and $28 \mathrm{GHz}$.
\end{abstract}

Keywords: umbrella monopole antenna, 5G applications, wideband, milimeter

\section{INTRODUCTION}

For some decades, the wireless mobile communication field has been developing. There are five generations of mobile communication systems from first-generation $(1 \mathrm{G})$, secondgeneration $(2 \mathrm{G})$, third-generation $(3 \mathrm{G})$, fourth-generation $(4 \mathrm{G})$, and fifth-generation (5G). The development of wireless communication networks has increased the demand for available bandwidth to provide high data rates [1].

Next-generation, 5G has become center stage in the wireless communication field. $5 \mathrm{G}$ technology is expected to have low latency and low power consumption. It is also desirable to provide high data rates, solid security, and highquality transmission for various applications [2]. Some of the $5 \mathrm{G}$ applications use the band of high-band in $28 \mathrm{GHz}$ and 24 $\mathrm{GHz}$ bands, Mid-band in $2.5 \mathrm{GHz}, 3.5 \mathrm{GHz}$, and $3.7-4.2 \mathrm{GHz}$ bands, and Low-band in $600 \mathrm{MHz}, 800 \mathrm{MHz}$, and $900 \mathrm{MHz}$ [3] [4]. The antenna is one of the components of $5 \mathrm{G}$ generation. Accordingly, the antenna should meet the requirements include large impedance bandwidth, very high gain, narrow beamwidth, and bream steerability [5]. Various antennas for 5G generation have been proposed [6]-[8]. In [6], a low-profile and wideband antenna with a measured bandwidth of $58.3 \%$ from $2.84 \mathrm{GHz}$ to $5.17 \mathrm{GHz}$. T- shaped patch antenna uses to cover impedance bandwidth of 26-40 GHz [7]. A transparent dual- polarized antenna array for 5G smartphone applications [8] achieved a wide frequency band of $23.5-32 \mathrm{GHz}$.

A monopole antenna is a good candidate. It can support wide impedance bandwidth, radiation stability, compact size, and omnidirectional radiation pattern. Various shapes of monopole antenna with coaxial, microstrip, or planar waveguide feeds have been proposed as candidates to fulfill these requirements [9]. In the literature, various researches have been done on UWB monopole antenna [10] [11] [12].

The choice of monopole antenna in various researches is because this type of antenna is easily modified and supported by wideband. One of the monopole antenna modifications uses the umbrella shape. It can increase the impedance bandwidth of monopole antenna such as [13] [14]. Ultra-wide bandwidth microstrip monopole antenna provides wide impedance bandwidth [13]. In [14], monopole antenna shows high potential for multi-band communication application.

In this paper, we designed and developed an umbrella monopole antenna for $5 \mathrm{G}$ applications. The proposed antenna has VSWR $<2 \mathrm{~dB}$, bandwidth of more than $10 \mathrm{GHz}$ and the radiation patterns are omnidirectional UWB. The antenna is simulated VSWR, surface current, and directivity. 


\section{ANTENNA DESIGN}

The proposed geometry of the umbrella monopole antenna at the design of 2-30 GHz is presented in Figure 1. The proposed antenna has a dimension of $50 \mathrm{~mm} \times 50 \mathrm{~mm} \times 1.6 \mathrm{~mm}$. The result of the development of four antennas is shown in Figure 2. The antenna geometry is designed on an FR4 substrate having $\varepsilon r=4.4, \tan \delta=0.02$, with a substrate thickness of 1.6 $\mathrm{mm}$. To obtain antennas with wide bandwidth and high gain, we designed four different models of Umbrella Monopole Antenna. They have different curvatures of umbrella patches.

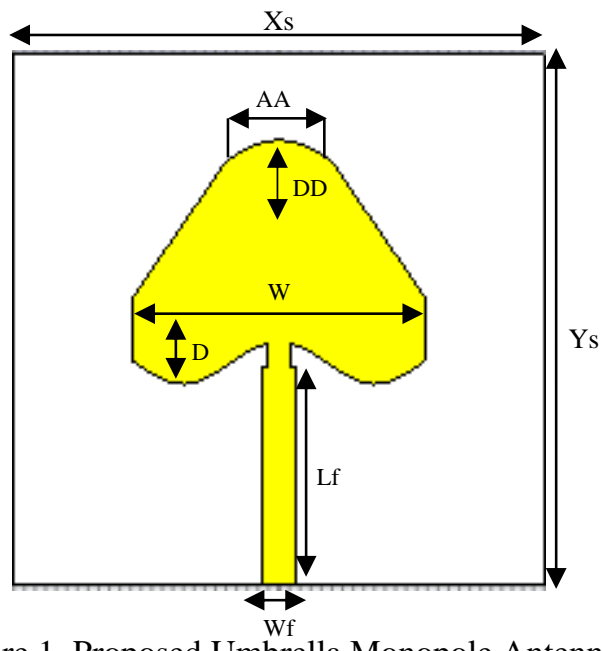

Figure 1. Proposed Umbrella Monopole Antenna

Table 1. Dimensions and Parameters of Umbrella Monopole Antenna

\begin{tabular}{cccc}
\hline \multicolumn{4}{c}{ Dimension Parameters (mm) } \\
\hline Ys & 50 & D & 1.25 \\
Xs & 50 & W & 27.5 \\
A & 20 & D & 4 \\
Wf & 3 & Lf & 28.1 \\
tsub & 1.6 & tpatch & 0.035 \\
\hline
\end{tabular}

The curvature of the patch follows the equation:

$y(t)=A\left(B+C \cos \left(\frac{D \pi t}{W}\right)\right.$

$\mathrm{A}, \mathrm{B}, \mathrm{C}, \mathrm{D}$, and $\mathrm{W}$ is the constant, that has a different value for UMA-A, UMA-B, UMA-C, and UMA-D. Figure 2. (c) describes the UMA-C. It has the widest umbrella width. It has the largest value of $\mathrm{W}$. It has $\mathrm{W}=40 \mathrm{~mm}$. Figure $2(\mathrm{~d})$ shows the UMA-D with $\mathrm{W}=40, \mathrm{~A}=22.5 \mathrm{~mm}$, and $\mathrm{D}=1 \mathrm{~mm}$. A is the constant that influences the height of the curvature and D interferes with the deep of curvature.
UMA-A, UMA-B, UMA-C, and UMA-D have different values of $\mathrm{A}, \mathrm{B}, \mathrm{C}, \mathrm{D}$, and $\mathrm{W}$ constant as shown in equation (1), but they have the same width of microstrip line feed.

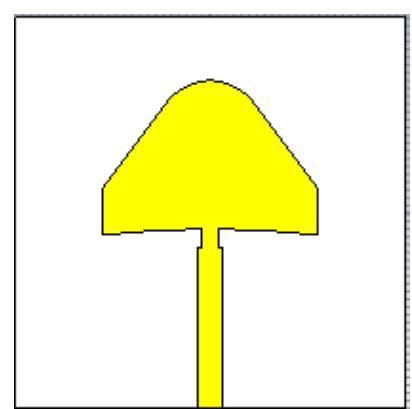

(a)

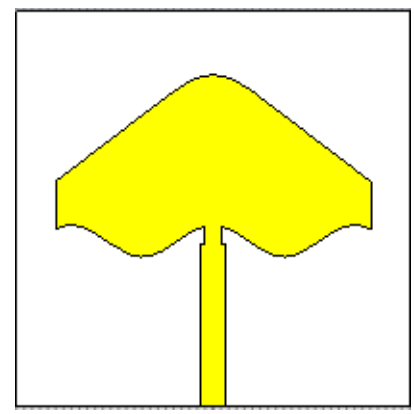

(c)

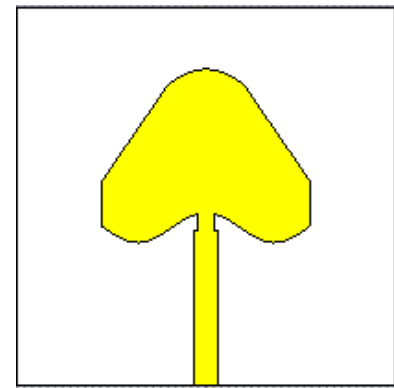

(b)

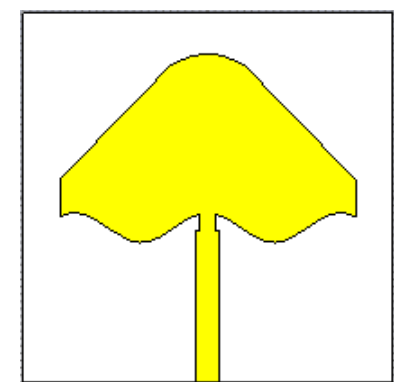

(d)
Figure 2. (a) UMA-A (b) UMA-B, (c) UMA-C, (d) UMA-D

\section{RESULT AND DISCUSSION}

The proposed umbrella monopole antenna is designed and simulated with CST Studio 2019. This antenna has covered from $2 \mathrm{GHz}$ to $30 \mathrm{GHz}$.

- VSWR

VSWR(Voltage Standing Waves Ratio) is the parameter of the antenna that determines the impedance bandwidth of the antenna.

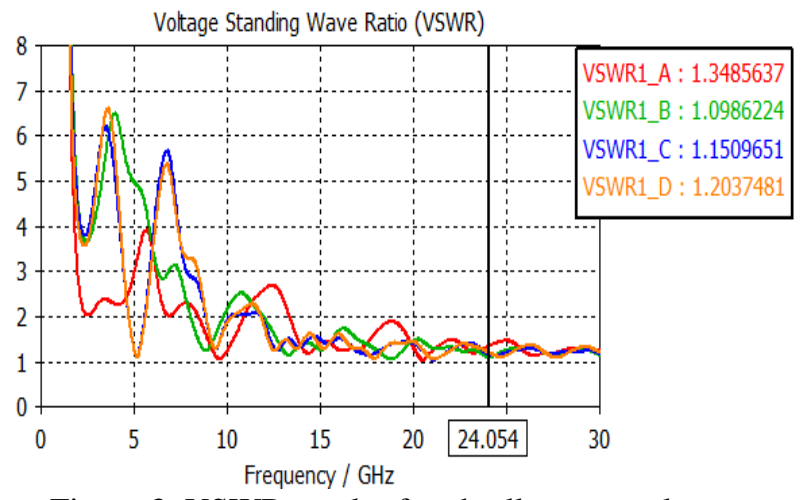

Figure 3. VSWR result of umbrella monopole antenna 
Figure 3. shows the VSWR for umbrella monopole antenna design UMA-A, UMA-B, UMA-C, and UMA-D. The value of the antenna is less than $2 \mathrm{~dB}$ in the frequency of $8 \mathrm{GHz}-30$ GHz (VSWR <2). But UMA-D has an impedance bandwidth of around $5 \mathrm{GHz}$. The simulation shows that the purposed antenna is suitable for 5G applications (base on ITU standard) [15].

\section{- Surface Current}

The surface current distribution is studied to understand the flowing of electric charge in the patch. The simulated surface current of UMA-A and UMA-B at $24.5 \mathrm{GHz}$ is shown in Figure 4. (a) and (b). Figure 4. (a) is shown that the primary current is on the ground and feeder.

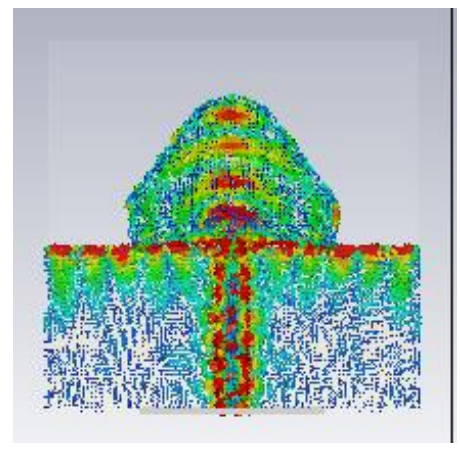

(a)

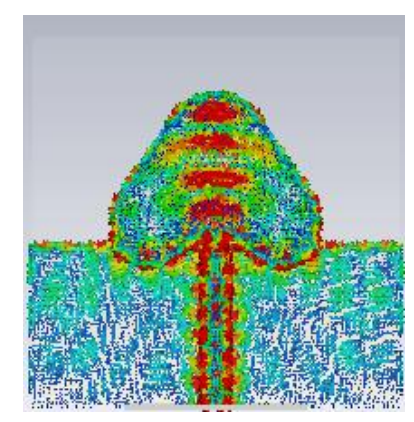

(b)
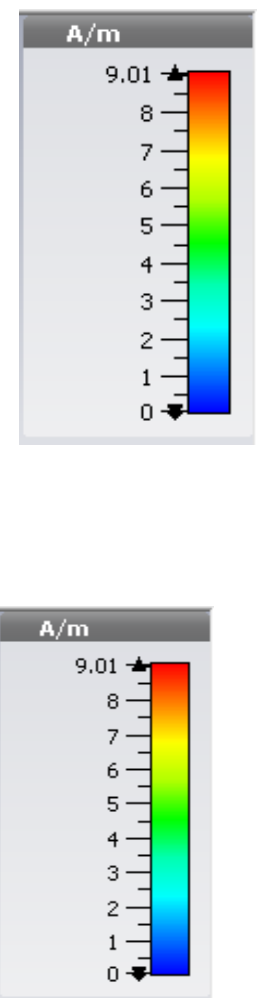

Figure 4. surface current (a) UMA-A, (b) UMA-B
In Figure 4. (b), by making a curve umbrella antenna patch in the bottom of umbrella, it increases the surface current density.
- Directivity

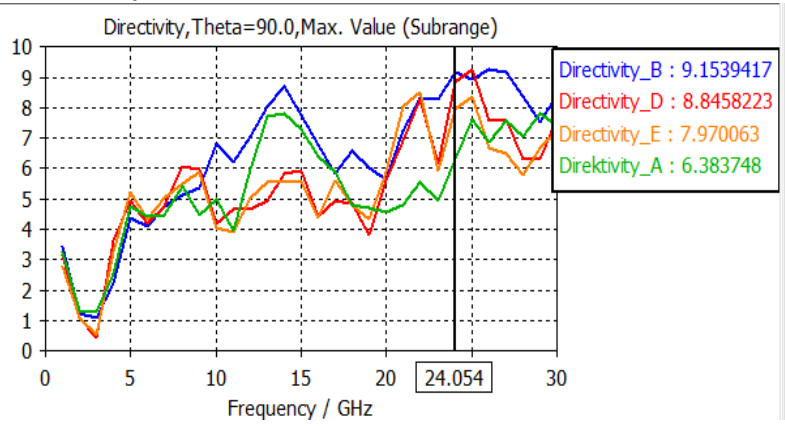

Figure 5. directivity result of umbrella monopole antenna

The simulation result of the directivity of the umbrella monopole antenna is shown in Figure 5. The Increasing of directivity is reached for UMA-A, UMA-C, UMA-D, and UMA-B, i.e: $6.38 \mathrm{dBi}, 7.97 \mathrm{dBi}, 8,84 \mathrm{dBi}$, and $9,15 \mathrm{dBi}$ respectively at $24 \mathrm{GHz}$. The wider umbrella width the worst directivity. The curvature of the antenna also influences the directivity of the antenna.

A comparison of the proposed antenna and other antennas is listed below.

Table 2. Comparison of proposed antenna with other antenna

\begin{tabular}{llll}
\hline \multicolumn{1}{c}{ No } & Size $\left(\mathbf{m m}^{2}\right)$ & Substrate & $\begin{array}{c}\text { Bandwidth } \\
(\mathbf{G H z})\end{array}$ \\
\hline$[16]$ & $65 \times 65$ & - & $1.84-3.6$ \\
\hline$[17]$ & $150 \times 75 \times 1.6$ & FR-4 & $3.4-5.1$ \\
\hline$[18]$ & $90 \times 90 \times 1.6$ & FR-4 & $3-9$ \\
\hline $\begin{array}{l}\text { Proposed } \\
\text { antenna }\end{array}$ & $50 \times 50 \times 1.6$ & FR-4 & $8-30$ \\
\hline
\end{tabular}

\section{CONCLUSION}

In this paper, an Umbrella Monopole Antenna (UMA) is designed, i.e: UMA-A, UMA-B, UMA-C, and UMA-D for 5G application. The proposed monopole antenna has a wide bandwidth. It operates at a frequency of $8 \mathrm{GHz}$ to $30 \mathrm{GHz}$ with VSWR $<2 \mathrm{~dB}$. An umbrella monopole antenna gets high directivity of $9.15 \mathrm{dBi}$ at $24.05 \mathrm{GHz}$. The proposed antenna can support for $5 \mathrm{G}$ applications at frequency $24 \mathrm{GHz}$ and $28 \mathrm{GHz}$.

\section{REFERENCES}

[1] Z. U. Khan, Q. H. Abbasi, A. Belenguer, T. H. Loh, and A. Alomainy, "Empty Substrate Integrated Waveguide Slot Antenna Array for 5G Applications," IEEE MTT-S International Microwave Workshop Series on 5G Hardware and System Technologies (IMWS-5G), 2018.

[2] M. Saini, S. Singh, A. K. Rai, and T. Goel, Novel CPW-fed UWB Monopole Patch Antenna for 5G Mobile Technology," Annual IEEE India Conference (INDICON), 2017. 
[3] FCC, "The FCC's 5G FAST Plan", Sep 2018 [Online]. Available: https://docs.fcc.gov/public/attachments/DOC-354326A1.pdf

[4] J. Choi, J. Park, W. Hwang, and W. Hong, "mmWave Double CavityBacked Slot Antenna featuring Electrically Small and Low-Profile," IEEE International Symposium on Antennas and Propagation and USNC-YRSI Radio Science Meeting, 2019.

[5] H. Ullah, F. A. Tahir, "An Electrically Small Semi-Circular Monopole Antenna for Broadband 5G Communications," IEEE International Symposium on Antennas and Propagation \& USNC/URSI National Radio Science Meeting, 2018.

[6] W. An, H. Fu, J. Ma, W. Chen, B. Feng, "Low-Profile and Wideband Microstrip Antenna with Stable Gain for 5G Wireless Applications," IEEE Antennas and Wireless Propagation Letters, 2018.

[7] S. F. Jilani, Q. H. Abbasi, A. Alomainy, "Inkjet-Printed MillimeterWave PET-Based Flexible Antenna for 5G Wireless Applications," IEEE MTT-S International Microwave Workshop Series on 5G Hardware and System Technologies (IMWS-5G), 2018.

[8] M. Stanley, Y. Huang, H. Wang, H. Zhou, A. Alieldin, S. Joseph, "A Transparent Dual-Polarized Antenna Array for 5G Smartphone Applications," IEEE International Symposium on Antennas and Propagation \& USNC/URSI National Radio Science Meeting, 2018.

[9] E. A.-Daviu, M. Sonkki, M. F.-Battaller, and E. Salonen, "UWB Differentially-fed Circular Monopole Antenna with Stable Radiation Pattern," IEEE $11^{\text {th }}$ European Conference on Antenna and Propagation (UECAP), 2017.

[10] D. Kumar, A. S. Siddiqui, H. P. Singh, and M. R. Tripathy, "Monopole Concept based Frequency Reconfigurable Patch Antenna for mm-Wave 5G-Band Applications," IEEE $6^{\text {th }}$ International Conference on Signal Processing and Integrated Network (SPIN), 2019.

[11] J. P. Princess, G. S. Let, P. Rizopackiamary, and J. Keziah, "Design of Dual-band Monopole Antenna for Mobile Communications," IEEE International Conference on Signal Processing and Communication (ICSPC - 2019), March 2019.

[12] W. Wang, X. Zhang, Y. Li, and W. Shen, “A Dual-Band Antenna Design for 5G Smartphone Applications," IEEE $11^{\text {th }}$ UK-Europe-China Workshop on Millimeter Waves and Terahertz Technologies (UCMMT), 2018.

[13] D. N. Elsheakh, H. A. Elsadek, E. A. Abdallah, M. F. Iskander, and H. Elhenawy, "Ultrawide Bandwidth Umbrella-Shaped Microstrip Monopole Antenna Using Spiral Artificial Magnetic Conductor (SAMC)," IEEE Antennas and Wireless Propagation Letters, Vol. 8, 2009.

[14] N. Mu, F. Zhang, and J. Wang, "A Modified Umbrella-Shaped Monopole Antenna for Multi-band Operation," IEEE CIE International Conference on Radar, 2011.

[15] H. Yon, M. T. Ali, M. A. Aris, B. Baharom, and N. A. N. Nasir, “A New Model Microstrip Antenna like Microphone Structure for 5G Application," Proceedings of 2018 IEEE International RF and Microwave Conference, 2018.

[16] N. Luo, Y. He, L. Zhang, S.- W. Wong, C. Li, and Y. Huang, "A Differential Broadband Dual-Polarized Base Station Antenna Element for 4G and 5G Applications," IEEE Computing, Communications and IoT Applications (ComComAp), 2019.

[17] J. Guo, L. Cui, C. Li, and B. Sun, "Side-edge Frame Printed Eight-port Dual-band Antenna Array for 5G Smartphone Applications, IEEE Trans. Antennas Propag, 2018.

[18] M. A. U. Haq, M. A. Khan, and M. R. Islam, "MIMO Antenna Design for Future 5G Wireless Communication Systems," In Software Engineering, Artificial Intelligence, Networking and Parallel/Distributed Computing; Springer: Cham, Switzerland, 2016. 